\title{
Is quality of diet associated with the microvasculature? An analysis of diet quality and retinal vascular calibre in older adults
}

\author{
Bamini Gopinath $^{1}$, Victoria M. Flood ${ }^{2}$, Jie Jin Wang $^{1,3}$, Elena Rochtchina ${ }^{1}$, Tien Y. Wong ${ }^{3,4}$ \\ and Paul Mitchell ${ }^{1 *}$ \\ ${ }^{1}$ Centre for Vision Research, Department of Ophthalmology and Westmead Millennium Institute, University of Sydney, \\ Westmead Hospital, Hawkesbury Road, Westmead, NSW 2145, Australia \\ ${ }^{2}$ Faculty of Health and Behavioural Sciences, University of Wollongong, Sydney, NSW, Australia \\ ${ }^{3}$ Department of Ophthalmology, Centre for Eye Research Australia, University of Melbourne, Australia \\ ${ }^{4}$ Singapore Eye Research Institute, National University of Singapore, Singapore, Singapore \\ (Submitted 31 May 2012 - Final revision received 22 August 2012 - Accepted 22 October 2012 - First published online 26 March 2013)
}

\section{Abstract}

It is unknown whether diet quality is associated with microvascular structure. The present study aimed to investigate the relationship between diet quality, reflecting adherence to dietary guidelines, with retinal microvascular calibre in older adults. The dietary data of 2720 Blue Mountains Eye Study participants, aged 50+ years, were collected using a semi-quantitative FFQ. A modified version of the Healthy Eating Index for Australians was developed to determine total diet scores (TDS). Fundus photographs were taken and retinal vascular calibre measured using computer-assisted techniques and summarised. After adjusting for age, sex, BMI, mean arterial blood pressure, smoking, serum glucose, leucocyte count and history of diagnosed stroke or CHD, persons with higher TDS had healthier retinal vessels cross-sectionally, with wider retinal arteriolar calibre (by approximately $3 \mu \mathrm{m}$, comparing the highest with the lowest quartile of TDS, $P_{\text {trend }}=0.0001$ ) and narrower retinal venular calibre (by approximately $2.5 \mu \mathrm{m} ; P_{\text {trend }}=0.02$ ). In younger subjects aged $\leq 65$ years, increasing TDS (lowest to the highest quartile) was associated with healthier retinal vessels: approximately $4.4 \mu \mathrm{m}$ wider retinal arteriolar $\left(P_{\text {trend }}<0.0001\right)$ and approximately $2.3 \mu \mathrm{m}$ narrower venular calibre $\left(P_{\text {trend }}=0.03\right)$. After multivariable adjustment, however, baseline TDS were not associated with retinal arteriolar $\left(P_{\text {trend }}=0.89\right)$ or venular calibre $\left(P_{\text {trend }}=0.25\right), 5$ years later. Also, baseline TDS were not associated with the 5 -year change in retinal arteriolar $(\beta=0 \cdot 14 ; P=0 \cdot 29)$ or venular calibre $(\beta=-0 \cdot 26 ; P=0 \cdot 07)$. Greater compliance with published dietary guidelines (higher diet quality) was cross-sectionally associated with wider retinal arterioles and narrower venules, indicating better retinal microvascular health.

\section{Key words: Diet quality: Total diet score: Retinal vascular calibre: Older adults: Blue Mountains Eye Study}

Large prospective studies have now demonstrated that a healthy diet is beneficial in reducing the risk of developing cardio-metabolic diseases such as diabetes and $\mathrm{CVD}^{(1-3)}$. Emerging data suggest that the relationship between dietary habits and CVD may, in part, be mediated via the microcirculation $^{(4-6)}$.

The microvasculature of the retina can be easily viewed and non-invasively imaged, and thus, can be a surrogate for the systemic microvasculature ${ }^{(7,8)}$. There is now a large body of accumulating evidence to suggest that some retinal microvascular changes (narrower retinal arteriolar calibre and wider venular calibre) are markers of poorer microvascular health and could predict systemic vascular diseases ${ }^{(9)}$, including hypertension, diabetes, stroke and $\operatorname{CVD}^{(7,10,11)}$.
There is some recent research that has examined the relationship of individual nutrients and foods on the retinal microvasculature. For instance, in older adults, aged 50 years and older, a high glycaemic index was associated with poorer retinal microvascular health (wider retinal venular calibre) ${ }^{(5)}$, while high fish consumption was associated with better retinal microvascular health (wider retinal arterioles and narrower venules) ${ }^{(4)}$.

Because nutrients are not consumed independently but together within a variety of foods in the diet ${ }^{(12)}$, there remains a need to examine overall diet quality in association with changes to the retinal microvascular structure. The measurement of overall diet quality has been previously used to determine the associations between whole foods and health

Abbreviations: BMES, Blue Mountains Eye Study; BP, blood pressure; TDS, total diet score.

*Corresponding author: P. Mitchell, fax +6129845 6117, email paul.mitchell@sydney.edu.org 
status $^{(13)}$. A healthy diet has been characterised in many ways, although there is no consensus about what best defines a healthy $\operatorname{diet}^{(14)}$. One approach groups foods 'a priori' that are representative of present nutrition knowledge in the form of dietary guidelines or other dietary recommendations ${ }^{(15)}$. This may be a more useful tool in public health practice to assess a population's adherence to present dietary guidelines based on empirical evidence ${ }^{(12)}$.

To the best of our knowledge, no population-based study has investigated the association between overall diet quality and microvascular health. We previously developed a tool ${ }^{(12)}$ modelled using both Australian and US diet quality indices $^{(16,17)}$. Using a large, representative cohort of adults aged 50 years and over, we aimed to assess the association between diet quality, using a tool based on dietary guidelines for the Australian population and retinal vascular calibre, a marker of systemic microvascular health.

\section{Methods}

\section{Study population}

The Blue Mountains Eye Study (BMES) is a population-based study of participants aged $\geq 49$ years, living in two postcodes of the Blue Mountains region, west of Sydney, Australia, which has studied age-related eye diseases and other health outcomes in an older urban Australian population. Details of

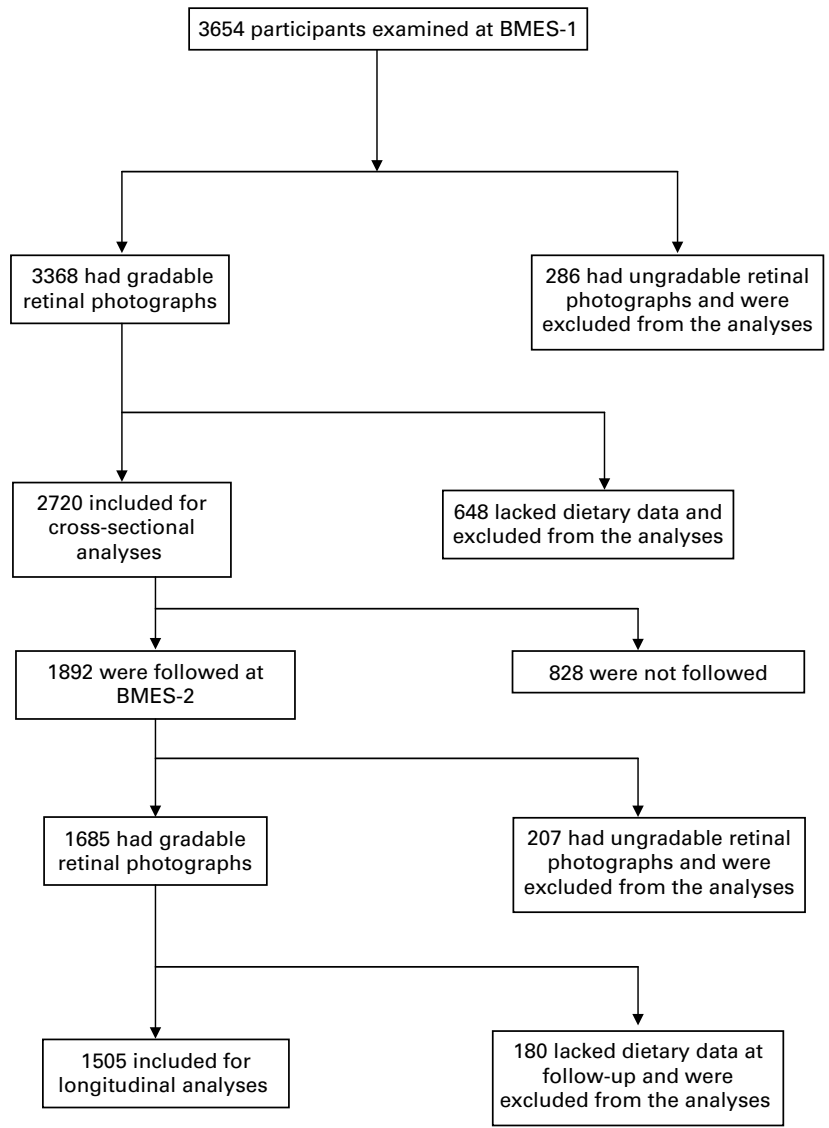

Fig. 1. Participation flowchart in the Blue Mountains Eye Study (BMES) from 1992-4 (BMES-1) to 1997-9 (BMES-2). the study methods have previously been described ${ }^{(18)}$. Fig. 1 shows the distribution of participation over a period of 5 years (from 1992-4 to 1997-9) in the BMES. The study was approved by the Human Research Ethics Committee of the University of Sydney, and was conducted adhering to the tenets of the Helsinki Declaration. Signed informed consent was obtained from all the participants at each examination.

\section{Dietary assessment}

At baseline, dietary data were collected using a 145-item self-administered FFQ, modified for the Australian diet and vernacular from an early Willett $\mathrm{FFQ}^{(19)}$ and including reference portion sizes. Participants used a nine-category frequency scale to indicate the usual frequency of consuming individual food items during the past year. The FFQ was validated by comparing nutrients from the FFQ to 4-d weighed food records collected over 1 year $(n$ 79). Most nutrient correlations were between 0.50 and 0.60 for energy-adjusted intakes, similar to other validated FFQ studies ${ }^{(20,21)}$. A dietitian coded data from the FFQ into a customised database that incorporated the Australian Tables of Food Composition 1990 (NUTTAB 90) $^{(22)}$.

A modified version of the Australian diet quality index ${ }^{(17)}$, based on the Dietary Guidelines for Australian Adults ${ }^{(23)}$ and the Australian Guide to Healthy Eating (AGHE) ${ }^{(24)}$, was used to establish the total diet score (TDS) assessing adherence to the Australian dietary guidelines. The methodology used to develop TDS has been previously reported ${ }^{(12)}$. Briefly, TDS were allocated for intakes of selected food groups and nutrients for each participant as described in the Dietary Guidelines for Australian Adults (details for FFQ food groupings available in Table S1, available online). The TDS is divided into ten components, and each component has a possible score ranging from 0 to 2. A maximum score of 2 was given to subjects who met the recommendations, with pro-rated scores for lower intakes (Table S1, available online). These were then summated, providing a final score ranging between 0 and 20, with higher scores indicating closer adherence to the dietary guidelines ${ }^{(12)}$.

The TDS account for both food intake and optimal choice, with scores allocated to reflect intake characteristics from both sources. Food intake scores were based on total intakes of vegetables, fruit, cereals and breads, meat, fish, poultry and/or alternatives and dairy products, as well as $\mathrm{Na}$, alcohol, sugar and extra foods. Optimal choices' scores determined intakes of foods with greater dietary benefits, including servings of whole-grain cereals, lean red meat, low- or reduced-fat milk $v$. whole milk, low saturated fat intake and fish consumption. Cut-points for scores were determined from recommended number of servings given in the AGHE with some exceptions ${ }^{(24)}$. We replaced the AGHE's recommended two servings per $d$ of fruit with three servings per $\mathrm{d}$ and the number of vegetables consumed per $\mathrm{d}$ from five to seven servings to allow for self-reported FFQ over-estimation, as determined by the validity study ${ }^{(21)}$. The alcohol cut-points reflect guidelines about alcohol consumption in Australia, in which it is recommended that men consume a maximum of two standard drinks per d (20 g of alcohol) and women one standard drink per d (10 g of alcohol) ${ }^{(23)}$. 
To follow dietary guideline recommendations as closely as possible, the non-dietary component of the Australian Guide to Healthy Eating, preventing weight gain, was included in the TDS. A maximum score of two points was allocated to this non-dietary component, which contributed to the maximum TDS of 20. Half the score was assigned to energy balance, calculated as the ratio of energy intake to energy expenditure, with a maximum score given for ratios falling between 0.76 and 1.24 , defined as the $95 \%$ confidence levels of agreement between energy intake and expenditure ${ }^{(25)}$. The other half of the score was assigned to leisure-time physical activity. Details of walking exercise and the performance of moderate or vigorous activities were used to calculate metabolic equivalents ${ }^{(26)}$. Subjects in the highest metabolic equivalents tertile scored one point, reducing to a 0 point score for subjects in the lowest metabolic equivalents tertile ${ }^{(12)}$.

\section{Retinal photography}

Detailed methods for grading the calibre of retinal arterioles and venules are described elsewhere ${ }^{(8)}$. In brief, at the baseline examination, $30^{\circ}$ photographs of the macula, optic disc and other retinal fields of both eyes were taken, after pupil dilation, using a Zeiss FF3 fundus camera (Zeiss). We used methods developed by the University of WisconsinMadison $^{(27)}$ to measure the internal calibre of retinal arterioles and venules from digitised photographs. These were then summarised using established formulas ${ }^{(28)}$ that account for branching patterns and combine individual vessel calibres into summary indices, and are presented as the central retinal artery equivalent or central retinal vein equivalent, representing the mean calibre of these vessels. Arterioleto-venule ratio was calculated from central retinal artery equivalent and central retinal vein equivalent. Intra- and inter-grader reliability of this method was high ${ }^{(28)}$, with quadratic weighted $\kappa$ values of 0.85 (central retinal artery equivalent) and 0.90 (central retinal vein equivalent) found for inter-grader reliability and between 0.80 to 0.93 and 0.80 to 0.92 for intra-grader reliability of the two graders, respectively. Vessel diameters for only right eyes were used in the analyses.

\section{Collection of potential confounder information}

At face-to-face interviews with trained interviewers, a comprehensive medical history, which included information about demographic factors, socio-economic characteristics and lifestyle factors like smoking, was obtained from all the participants. History of smoking was defined as never, past or current smoking. Current smokers included those who had stopped smoking within the past year. Information on physician-diagnosed history of stroke and CHD were also obtained. BMI was calculated as weight divided by height squared $\left(\mathrm{kg} / \mathrm{m}^{2}\right)$. Blood pressure (BP) was measured using standard auscultatory methods. Mean arterial BP was defined as $0.33 \times$ systolic $\mathrm{BP}+0.67 \times$ diastolic $\mathrm{BP}$. Hypertension was categorised into stage I (140/90-160/100) and stage II ( $>160 / 100$ or treated). Fasting blood samples were processed the same day for leucocyte count and glucose. Diabetes was defined either by history or from fasting blood glucose $\geq 7 \cdot 0 \mathrm{mmol} / \mathrm{l}$.

\section{Statistical analysis}

SAS statistical software (SAS Institute, Inc.) version 9.1 was used for analyses, including $t$ tests, $\chi^{2}$ tests and linear regression analyses. Retinal vessel calibre associations with TDS were assessed as continuous variables (per unit increase in TDS) using linear regression models. ANCOVA (general linear model) was used to assess associations between TDS, with adjusted means of retinal arteriolar and venular calibre. We conducted two analyses. First, the cross-sectional association of diet score and retinal vessel calibre was examined in linear regression models and general linear model using baseline data and was initially adjusted for age and sex, and then further adjusted for BMI, mean arterial BP, smoking, serum glucose, leucocyte count and history of diagnosed stroke and CHD for cross-sectional analyses. We then conducted longitudinal analyses that examined baseline dietary intake in relation to retinal vascular calibre measured at the 5-year follow-up as well as 5-year change in retinal vascular calibre, defined as the difference in the calibre measures between baseline and the 5-year follow-up visits and adjusted for age, sex, smoking, mean arterial BP, BMI and baseline retinal vascular calibre. Additionally, to assess the vessel calibre values while avoiding collinearity between arteriolar and venular diameters ${ }^{(29)}$, we adjusted arteriolar diameter for venular diameter, and venular diameter for arteriolar diameter, using the residual method suggested by Willett ${ }^{(30)}$. We also tested for statistically significant interactions between age and TDS in relation to retinal vascular calibre by adding a product term for age and TDS in the final, multivariable model. Linear regression analyses indicated a marginally significant interaction between age and TDS in association with retinal arteriolar calibre $\left(P_{\text {interaction }}=0.05\right)$. Therefore, supplementary analyses were performed in subgroups stratified by age, i.e. age $\leq 65$ and $>65$ years.

\section{Results}

Of the 3654 participants examined at BMES-1, 2720 had complete data on retinal vascular calibre and TDS data (Fig. 1). Study participants were, on average, overweight (BMI of $27.6 \mathrm{~kg} / \mathrm{m}^{2}$ ) and $71 \%$ had either stage I or II hypertension (Table 1). Mean TDS at baseline was $9 \cdot 47$ (SD 2.2).

\section{Cross-sectional association between total diet score and retinal vascular calibre}

The distribution of nutrient and food group intake by quartiles of TDS is shown in Table 2. Comparing the highest with the lowest quartile of TDS, a significant widening (approximately $3 \mu \mathrm{m})$ of mean retinal arteriolar calibre was observed (multivariable-adjusted $P_{\text {trend }}=0.0001$; Table 3). Conversely, increasing TDS was associated with narrower mean retinal venular calibre (multivariable-adjusted $P_{\text {trend }}=0 \cdot 02$; Table 3 ). 
Table 1. Demographic and clinical characteristics of Blue Mountains Eye Study participants included for analyses (Mean values and standard deviations; number of participants and percentages)

\begin{tabular}{|c|c|c|}
\hline \multirow[b]{2}{*}{ Characteristics } & \multicolumn{2}{|c|}{$\begin{array}{l}\text { Participants } \\
\text { (n 2720) }\end{array}$} \\
\hline & Mean & SD \\
\hline Age (years) & $65 \cdot 0$ & $9 \cdot 1$ \\
\hline \multicolumn{3}{|l|}{ Sex } \\
\hline \multicolumn{3}{|l|}{ Male } \\
\hline$n$ & \multicolumn{2}{|c|}{1196} \\
\hline$\%$ & \multicolumn{2}{|c|}{$44 \cdot 0$} \\
\hline \multicolumn{3}{|l|}{ Current smoker } \\
\hline$n$ & \multirow{2}{*}{\multicolumn{2}{|c|}{379}} \\
\hline$\%$ & $14 \cdot 3$ & \\
\hline Mean arterial blood pressure $(\mathrm{mmHg})$ & 103.9 & $12 \cdot 2$ \\
\hline Serum glucose $(\mathrm{mmol} / \mathrm{l})$ & $5 \cdot 2$ & 1.5 \\
\hline BMI $\left(\mathrm{kg} / \mathrm{m}^{2}\right)$ & $27 \cdot 6$ & 4.8 \\
\hline \multicolumn{3}{|l|}{ History of CHD } \\
\hline$n$ & \multicolumn{2}{|c|}{397} \\
\hline$\%$ & \multicolumn{2}{|c|}{$14 \cdot 6$} \\
\hline \multirow{2}{*}{\multicolumn{3}{|c|}{ History of stroke }} \\
\hline$n$ & & 121 \\
\hline$\%$ & \multicolumn{2}{|c|}{4.5} \\
\hline \multicolumn{3}{|l|}{ History of hypertension* } \\
\hline$n$ & \multirow{2}{*}{\multicolumn{2}{|c|}{1916}} \\
\hline$\%$ & & $70 \cdot 5$ \\
\hline \multicolumn{3}{|l|}{ History of diabetes } \\
\hline$n$ & \multicolumn{2}{|c|}{196} \\
\hline$\%$ & \multicolumn{2}{|c|}{$7 \cdot 2$} \\
\hline
\end{tabular}

After multivariable adjustment, each unit increase in TDS was associated with a $0.54 \mu \mathrm{m}$ increase in mean retinal arteriolar calibre $(P=0.0001)$ and a $0.44 \mu \mathrm{m}$ decrease in mean retinal venular calibre $(P=0 \cdot 01)$.

Among those aged $\leq 65$ years, a significant, approximately $4.4 \mu \mathrm{m}$ widening of mean retinal arteriolar $\left(P_{\text {trend }}<0.0001\right)$ and approximately $2.3 \mu \mathrm{m}$ narrowing of mean retinal venular vessel diameter $\left(P_{\text {trend }}=0.03\right)$ was associated with increasing TDS from the lowest to the highest quartiles (Table 4). Nonsignificant associations were observed among persons aged $>65$ years (Table 4 )

\section{Longitudinal association between total diet scores and retinal vascular calibre}

We analysed the temporal relationship between baseline TDS and retinal vascular calibre measured at the 5-year follow-up ( $n$ 1505). Mean TDS at the 5-year follow-up was 9.51 (SD 2.2), and a change of $-0.04(P=0.45)$ in mean TDS was observed over the period of 5 years. Change was normally distributed with SD of 2 , and approximately $67 \%$ of the participants had a change in TDS of $<2$ units. After adjusting for age, sex, smoking, mean arterial BP, BMI and baseline retinal vascular calibre, baseline TDS were not associated with retinal arteriolar calibre $\left(P_{\text {trend }}=0.89\right)$ or venular calibre $\left(P_{\text {trend }}=0 \cdot 25\right)$ measured 5 years later. Additionally, after multivariable adjustment, baseline TDS were not associated with change from baseline to 5-year follow-up examination in retinal arteriolar calibre $(P=0 \cdot 29)$ or venular calibre $(P=0 \cdot 07)$.

\section{Discussion}

The potential for microvascular benefits from a higher overall diet quality among adults has not previously been explored. We found that consumption of a high-quality diet, consistent with the national dietary guidelines for Australian adults, was associated with better retinal microvascular health (wider mean retinal arteriolar calibre and narrower retinal venular diameter). These associations were independent of CVD risk factors (e.g. smoking and BMI) and morbidity (e.g. CHD). Stratified analyses suggest that these associations

Table 2. Dietary intakes of nutrients and food groups stratified by quartiles of total diet score at baseline among Blue Mountains Eye Study participants in 1992-4 ( $n$ 2720)

(Mean values and standard deviations)

\begin{tabular}{|c|c|c|c|c|c|c|c|c|}
\hline \multirow[b]{3}{*}{ Nutrients/food groups (g/d) } & \multicolumn{8}{|c|}{ Total diet score } \\
\hline & \multicolumn{2}{|c|}{$\begin{array}{l}\text { First quartile } \\
\quad(n 676)\end{array}$} & \multicolumn{2}{|c|}{$\begin{array}{l}\text { Second quartile } \\
\quad(n 683)\end{array}$} & \multicolumn{2}{|c|}{$\begin{array}{l}\text { Third quartile } \\
\quad(n 676)\end{array}$} & \multicolumn{2}{|c|}{$\begin{array}{l}\text { Fourth quartile } \\
\qquad(n 685)\end{array}$} \\
\hline & Mean & SD & Mean & SD & Mean & SD & Mean & SD \\
\hline Total energy & 8754 & 2920 & 8799 & 2813 & 8378 & 2480 & 8176 & 1959 \\
\hline Total carbohydrates & $228 \cdot 3$ & 84.8 & $241 \cdot 1$ & $83 \cdot 7$ & 232.9 & $77 \cdot 9$ & $239 \cdot 1$ & $70 \cdot 7$ \\
\hline Dietary Gl & 58.6 & 4.5 & $57 \cdot 0$ & 4.4 & 56.0 & 4.4 & $54 \cdot 8$ & 4.0 \\
\hline Dietary GL & $133 \cdot 6$ & $49 \cdot 4$ & $137 \cdot 6$ & 48.5 & $130 \cdot 5$ & $44 \cdot 7$ & 130.5 & 38.8 \\
\hline Total sugars & $123 \cdot 3$ & 54.6 & $129 \cdot 3$ & $55 \cdot 5$ & $124 \cdot 2$ & 51.5 & $123 \cdot 1$ & 47.5 \\
\hline Total fibre & $22 \cdot 6$ & 9.8 & $26 \cdot 9$ & $10 \cdot 2$ & $28 \cdot 2$ & $10 \cdot 0$ & 32.9 & $11 \cdot 1$ \\
\hline Total fat & $81 \cdot 9$ & $32 \cdot 6$ & $81 \cdot 1$ & $31 \cdot 1$ & 74.8 & $27 \cdot 5$ & $66 \cdot 7$ & 21.9 \\
\hline Saturated fat & 33.9 & $15 \cdot 6$ & $32 \cdot 7$ & $14 \cdot 3$ & $28 \cdot 7$ & 11.9 & $24 \cdot 1$ & 9.4 \\
\hline Monounsaturated fat & $29 \cdot 1$ & 11.6 & $28 \cdot 6$ & $11 \cdot 3$ & $26 \cdot 5$ & $10 \cdot 2$ & $23 \cdot 8$ & $8 \cdot 3$ \\
\hline Polyunsaturated fat & $12 \cdot 3$ & $5 \cdot 6$ & $12 \cdot 9$ & $5 \cdot 6$ & $12 \cdot 9$ & 5.9 & $12 \cdot 5$ & $5 \cdot 1$ \\
\hline Vegetables & $375 \cdot 8$ & 191.5 & $430 \cdot 2$ & $195 \cdot 7$ & $456 \cdot 2$ & $168 \cdot 5$ & $504 \cdot 1$ & 198.5 \\
\hline Fruits & $237 \cdot 7$ & $222 \cdot 2$ & 322.5 & $226 \cdot 0$ & $362 \cdot 1$ & $268 \cdot 2$ & $438 \cdot 7$ & $257 \cdot 1$ \\
\hline Breads and cereals & $166 \cdot 0$ & $115 \cdot 1$ & $205 \cdot 5$ & 121.9 & 218.9 & $127 \cdot 5$ & $272 \cdot 3$ & 134.5 \\
\hline Fish & $17 \cdot 3$ & 18.5 & $23 \cdot 3$ & $22 \cdot 7$ & 29.7 & $26 \cdot 8$ & 38.5 & $35 \cdot 3$ \\
\hline Nuts & $6 \cdot 8$ & $12 \cdot 4$ & 6.9 & $10 \cdot 2$ & $7 \cdot 1$ & $13 \cdot 0$ & 7.4 & 11.3 \\
\hline
\end{tabular}

Gl, glycaemic index; GL, glycaemic load. 
Table 3. Cross-sectional association between total diet score and retinal vascular calibre among Blue Mountains Eye Study participants in 1992-4 (n 2720)

(Adjusted mean values and $95 \%$ confidence intervals)

\begin{tabular}{|c|c|c|c|c|c|}
\hline \multirow[b]{2}{*}{ Total diet score (range) } & \multirow[b]{2}{*}{$n$} & \multicolumn{2}{|c|}{ Age-sex-adjusted } & \multicolumn{2}{|c|}{ Multivariable-adjusted ${ }^{*}$} \\
\hline & & Mean & $95 \% \mathrm{Cl}$ & Mean & $95 \% \mathrm{Cl}$ \\
\hline \multicolumn{6}{|l|}{ Retinal arteriolar calibre $(\mu \mathrm{m})$} \\
\hline First quartile $(2.97-7.70)$ & 676 & $185 \cdot 4$ & $184 \cdot 3,186 \cdot 5$ & 184.9 & $183 \cdot 7,186 \cdot 1$ \\
\hline Second quartile $(7 \cdot 70-9 \cdot 20)$ & 683 & 187.4 & $186 \cdot 3,188.5$ & $187 \cdot 3$ & $186 \cdot 2,188 \cdot 5$ \\
\hline Third quartile $(9 \cdot 20-10 \cdot 77)$ & 676 & 187.8 & $186.7,188.9$ & 187.9 & $186 \cdot 8,189 \cdot 1$ \\
\hline Fourth quartile $(10.80-15.40)$ & 685 & $188 \cdot 4$ & $187 \cdot 3,189.5$ & $188 \cdot 3$ & $187 \cdot 1,189 \cdot 4$ \\
\hline$P$ value for trend & & & 0.0003 & & 0.0001 \\
\hline \multicolumn{6}{|l|}{ Retinal venular calibre $(\mu \mathrm{m})$} \\
\hline First quartile $(2.97-7.70)$ & 676 & $227 \cdot 0$ & $225 \cdot 7,228 \cdot 2$ & $226 \cdot 7$ & $225 \cdot 4,228 \cdot 1$ \\
\hline Second quartile $(7 \cdot 70-9 \cdot 20)$ & 683 & $225 \cdot 2$ & $223 \cdot 9,226 \cdot 4$ & 224.9 & $223 \cdot 6,226 \cdot 2$ \\
\hline Third quartile $(9 \cdot 20-10 \cdot 77)$ & 676 & 223.9 & $222 \cdot 6,225 \cdot 1$ & $224 \cdot 1$ & $222 \cdot 8,225 \cdot 4$ \\
\hline Fourth quartile $(10.80-15.40)$ & 685 & 223.6 & $222 \cdot 4,224 \cdot 9$ & 224.4 & $223 \cdot 1,225 \cdot 7$ \\
\hline$P$ value for trend & & & $<0.0001$ & & 0.02 \\
\hline
\end{tabular}

were stronger in the younger ( $\leq 65$ years) than in the older ( $>65$ years) persons. However, baseline TDS was associated neither with retinal vascular calibre measures 5 years later, nor with the 5-year change in retinal vascular calibre.

Retinal vascular calibre changes reflect ageing and cumulative response to CVD and related risk factors, inflammation, NO-dependent endothelial dysfunction and other processes ${ }^{(31)}$. Narrower retinal arteriolar calibre has been found to be associated with older age; higher levels of past, current, and future BP; and obesity, and predicts the incidence of diabetes and $\mathrm{CHD}^{(7,10,32-37)}$. Wider retinal venular calibre, in contrast, has been found to be associated with impaired fasting glucose and diabetes; dyslipidaemia; obesity; systemic marker of inflammation, endothelial dysfunction and cigarette smoking; and to predict the risk of stroke and $\mathrm{CHD}^{(10,31-33,35,37-39)}$. The TDS, which encompasses several dimensions of a health-promoting diet, was associated with healthier retinal vessels (wider retinal arteriolar calibre and narrower venular calibre). These data extend our previous findings from the BMES cohort, showing that high fish consumption was associated with better retinal vascular health (wider retinal arterioles and narrower retinal venules) ${ }^{(4)}$, while high-glycaemic index and low-cereal fibre diets were associated with worse retinal vascular health (wider retinal venular calibre) $^{(5)}$

The physiological influence of diet on the retinal microcirculation is likely to be cumulative, long-term and probably complex ${ }^{(6)}$. A recent Korean study ${ }^{(13)}$ demonstrated that different food-based diet quality scores were inversely related to biomarkers of oxidative stress in adults. Additionally, Fung et al. ${ }^{(40)}$ showed that higher diet quality scores were associated with reduced endothelial dysfunction. Reduced oxidative stress and improved endothelial function have previously been shown to elicit the dilation of retinal arterioles $^{(41)}$ and could be potential mechanisms that mediate the positive relation between higher diet quality and retinal arteriolar diameter.

Higher diet quality scores, characterised by high intake of fruits, vegetables, whole grains, nuts and fish, were previously shown to be associated with lower concentrations of

Table 4. Cross-sectional association between total diet score and retinal vascular calibre stratified by age among Blue Mountains Eye Study participants in 1992-4 (n 2720)

(Adjusted mean* values and $95 \%$ confidence intervals)

\begin{tabular}{|c|c|c|c|c|c|c|}
\hline \multirow[b]{2}{*}{ Total diet score (range) } & \multicolumn{3}{|c|}{ Participants aged $\leq 65$ years } & \multicolumn{3}{|c|}{ Participants aged $>65$ years } \\
\hline & $n$ & Adjusted mean & $95 \% \mathrm{Cl}$ & $n$ & Adjusted mean & $95 \% \mathrm{Cl}$ \\
\hline \multicolumn{7}{|l|}{ Retinal arteriolar calibre $(\mu \mathrm{m})$} \\
\hline First quartile $(2.97-7.70)$ & 383 & $185 \cdot 1$ & $183 \cdot 5,186 \cdot 6$ & 293 & $185 \cdot 0$ & $183 \cdot 1,186 \cdot 9$ \\
\hline Second quartile $(7 \cdot 70-9 \cdot 20)$ & 340 & $188 \cdot 1$ & $186 \cdot 6,189 \cdot 7$ & 343 & $186 \cdot 4$ & $184 \cdot 8,188 \cdot 1$ \\
\hline Third quartile $(9 \cdot 20-10 \cdot 77)$ & 380 & $189 \cdot 4$ & $188 \cdot 0,190 \cdot 9$ & 296 & $186 \cdot 1$ & $184 \cdot 3,187 \cdot 8$ \\
\hline Fourth quartile $(10.80-15.40)$ & 346 & $189 \cdot 4$ & $187.9,191 \cdot 0$ & 339 & $186 \cdot 9$ & $185 \cdot 2,188 \cdot 6$ \\
\hline$P$ value for trend & \multicolumn{3}{|c|}{$<0.0001$} & & \multicolumn{2}{|c|}{0.20} \\
\hline \multicolumn{7}{|l|}{ Retinal venular calibre $(\mu \mathrm{m})$} \\
\hline First quartile (2.97-7.70) & 383 & $228 \cdot 0$ & $226 \cdot 2,229 \cdot 7$ & 293 & $225 \cdot 6$ & $223 \cdot 5,227 \cdot 8$ \\
\hline Second quartile $(7 \cdot 70-9 \cdot 20)$ & 340 & 226.9 & $225 \cdot 1,228 \cdot 7$ & 343 & $222 \cdot 8$ & $221 \cdot 0,224 \cdot 7$ \\
\hline Third quartile $(9.20-10.77)$ & 380 & 224.5 & $222 \cdot 9,226 \cdot 2$ & 296 & 223.8 & $221 \cdot 7,225 \cdot 8$ \\
\hline Fourth quartile $(10.80-15.40)$ & 346 & $225 \cdot 7$ & $224 \cdot 0,227.5$ & 339 & 222.6 & $220 \cdot 7,224.5$ \\
\hline$P$ value for trend & \multicolumn{3}{|c|}{0.03} & & \multicolumn{2}{|c|}{0.13} \\
\hline
\end{tabular}

*Adjusted for age, sex, fellow retinal vascular calibre, BMI, smoking, mean arterial blood pressure, serum glucose, leucocyte count and history of diagnosed stroke and CHD. 
inflammatory markers such as IL-6 and C-reactive protein ${ }^{(40,42)}$. The retinal microvasculature is known to be influenced by inflammatory factors ${ }^{(43)}$, and could be a likely pathway by which diet quality mediates retinal microvascular signs, particularly retinal venular narrowing, in adults with higher diet quality ${ }^{(43)}$. However, in the present study, adjusting for leucocyte count (an inflammatory marker) in the final, multivariable model only slightly reduced the magnitude of retinal venular narrowing, i.e. approximately 2.5 compared with approximately $2 \cdot 3 \mu \mathrm{m}$. This suggests that other inflammatory markers or another pathway independent of inflammation might mediate the association between diet quality and retinal venular calibre. Further studies are warranted to clarify the underlying causal mechanisms.

Associations between diet quality and retinal vessel diameter were primarily observed among adults aged $\leq 65$ years. This observed association was not due to a significant difference in TDS between participants aged $\leq 65$ and $>65$ years, $9 \cdot 19 v \cdot 9 \cdot 35$, respectively $(P=0.06)$. We speculate, therefore, that the protective influence of a healthy diet may decline with age due to age-related changes in small vessel walls, leading to rigidity (sclerosis) of small vessels.

We highlight that the differences in arteriolar calibre between the lowest and highest quartiles of TDS were modest (approximately $2-3 \mu \mathrm{m}$ ). Nevertheless, we and others have shown that even such small reductions in retinal arteriolar calibre can be associated with moderate changes in BP, e.g. each $10 \mathrm{mmHg}$ increase in systolic BP was associated with a $1.1 \mu \mathrm{m}$ reduction in arteriolar calibre ${ }^{(5,44)}$. The relationship of arteriolar calibre is also graded and small differences in adulthood can translate into meaningful differences in CHD risk $^{(10)}$. Therefore, the present findings could have relevant public health implications, as encouragement of healthy lifestyle choices and nutritional patterns could potentially prevent subclinical changes in the microvasculature and have a role in the reduction of CVD morbidity and mortality risk.

The lack of a longitudinal association between TDS and retinal vascular calibre over a 5-year interval is not completely unexpected. In general, retinal microvascular structure over a lifetime does not change appreciably with the cumulative effects of CVD risk factors; for instance, BP measured 9 years ago was associated with narrower retinal arterioles, independent of current BP levels in adults ${ }^{(45)}$. This suggests that the observed cross-sectional association between diet quality and retinal vascular calibre is likely to represent the cumulative beneficial effects of a healthy diet rather than a single 'snapshot' of the current diet. Moreover, the FFQ is limited as it only measures diet at one time and not over a lifetime; however, older adults often have established eating patterns that remain constant over time ${ }^{(46)}$, which further supports our hypothesis on the cumulative effects of a healthy diet on the retinal microvasculature. Second, the follow-up period of 5 years may not be sufficiently long enough to observe any sustained effects of diet quality on the retinal microvasculature. This notion agrees with other population-based studies, which did not find significant associations between diet quality and 4-year all-circulatory disease mortality ${ }^{(47)}$ and risk of ischaemic and haemorrhagic strokes $^{(48)}$. Third, the lack of a prospective link could be due to a low level of compliance to dietary guidelines in our cohort. Our earlier study ${ }^{(12)}$ showed poor compliance with dietary guidelines in the BMES cohort, with the maximum score reaching approximately $75 \%$ compliance to dietary guidelines, which is consistent with other findings in the Australian population ${ }^{(49)}$. Therefore, if overall diets were improved, we might have observed an appreciable influence of diet quality on the retinal microcirculation. Finally, the dietary guidelines for Australian adults (used to construct the TDS) were developed to provide guidelines for diet targeting overall health and well-being, but they are not disease specific and may provide protective benefits for some diseases and not others $^{(50)}$. Hence, the non-significant temporal findings observed in the present study do not necessarily suggest that a healthy dietary pattern is ineffective in preventing retinal microvascular disease, but rather a different definition of a healthy diet may be needed to achieve optimal effects ${ }^{(14,51)}$.

Strengths of the present study include its population-based sample, use of a validated food questionnaire to collect dietary data, availability of rich confounder information and the quantitative computer-assisted measurement of retinal vessel diameters from digitised fundus photographs. Limitations using FFQ for self-reported dietary intake can underestimate energy intake ${ }^{(46)}$ or overestimate fruit, vegetable and dairy product intakes ${ }^{(50)}$. However, a comprehensive assessment of the whole diet is less subject to measurement error than is the assessment of energy intake alone ${ }^{(14,52)}$. That is because even when people under- or over-estimate the total amount they consume, the ratios of the foods that they self-report are still likely to be reflective of actual consumption ${ }^{(14)}$. An additional limitation is the assumption that the dietary guidelines used to define diet quality indices are based on the best-available scientific knowledge, which may not necessarily be correct, as it is difficult to keep the dietary guidelines up to date ${ }^{(53)}$. Finally, we cannot exclude the possibility of residual confounding from unmeasured lifestyle (e.g. sedentary behaviours) or societal parameters that could have influenced observed associations with the retinal vascular structure.

In summary, we found that diet quality, measured with a TDS reflecting present intake guidelines, could influence the retinal microvascular health of older adults, with better diet quality associated with better retinal microvascular health (wider retinal arterioles and narrower venules). Additional research is warranted to assess whether adherence to dietary guidelines is associated with the retinal microvascular structure in the longer term, and the possible public health and clinical implications of such relationships.

\section{Supplementary material}

To view supplementary material for this article, please visit http://dx.doi.org/10.1017/S0007114512005491

\section{Acknowledgements}

The authors' contributions were as follows: B. G. and P. M. aided in study concept and design; P. M. carried out 
acquisition of data; analysis and interpretation of data was done by B. G., E. R., J. J. W., T. Y. W. and P. M.; drafting of the manuscript was done by B. G. and P. M.; B. G., V. M. F., E. R., J. J. W., T. Y. W. and P. M. carried out critical revision of the manuscript. We would like to acknowledge Joanna Russell who also contributed to the development of the TDS. The authors declare no conflict of interest. Sources of funding are as follows: The BMES was supported by the Australian National Health and Medical Research Council (grant no. 974159, 991407, 211069 and 262120) and Westmead Millennium Institute. This work was also supported by the Meat and Livestock Australia. B. G. is supported by a National Health and Medical Research Council Centre for Clinical Research Excellence grant (grant no. 529923).

\section{References}

1. Ford ES, Bergmann MM, Kroger J, et al. (2009) Healthy living is the best revenge: findings from the European Prospective Investigation Into Cancer and Nutrition-Potsdam study. Arch Intern Med 169, 1355-1362.

2. Gopinath B, Rochtchina E, Flood VM, et al. (2010) Healthy living and risk of major chronic diseases in an older population. Arch Intern Med 170, 208-209.

3. Stampfer MJ, Hu FB, Manson JE, et al. (2000) Primary prevention of coronary heart disease in women through diet and lifestyle. $N$ Engl J Med 343, 16-22.

4. Kaushik S, Wang JJ, Flood V, et al. (2007) Frequency of fish consumption, retinal microvascular signs and vascular mortality. Microcirculation 15, 27-36.

5. Kaushik S, Wang JJ, Wong TY, et al. (2009) Glycemic index, retinal vascular caliber, and stroke mortality. Stroke $\mathbf{4 0}$, 206-212.

6. Serre K \& Sasongko MB (2012) Modifiable lifestyle and environmental risk factors affecting the retinal microcirculation. Microcirculation 19, 29-36.

7. Wong TY \& Mitchell P (2007) The eye in hypertension. Lancet 369, 425-435.

8. Wang JJ, Mitchell P, Leung $\mathrm{H}$, et al. (2003) Hypertensive retinal vessel wall signs in a general older population: the Blue Mountains Eye Study. Hypertension $\mathbf{4 2}$, 534-541.

9. Wong TY \& Mitchell P (2004) Hypertensive retinopathy. $N$ Engl J Med 351, 2310-2317.

10. McGeechan K, Liew G, Macaskill P, et al. (2009) Metaanalysis: retinal vessel caliber and risk for coronary heart disease. Ann Intern Med 151, 404-413.

11. Wang JJ, Baker ML, Hand PJ, et al. (2010) Transient ischemic attack and acute ischemic stroke: associations with retinal microvascular signs. Stroke 42, 404-408.

12. Russell J, Flood V, Rochtchina E, et al. (2013) Adherence to dietary guidelines and 15-year risk of all-cause mortality. BrJ Nutr 109, 547-555.

13. Kim JY, Yang YJ, Yang YK, et al. (2011) Diet quality scores and oxidative stress in Korean adults. Eur J Clin Nutr $\mathbf{6 5}$, $1271-1278$.

14. Zamora D, Gordon-Larsen P, Jacobs DR, et al. (2010) Diet quality and weight gain among black and white young adults: the Coronary Artery Risk Development in Young Adults (CARDIA) Study (1985-2005). Am J Clin Nutr 92, $784-793$.

15. Waijers PM, Feskens EJ \& Ocke MC (2007) A critical review of predefined diet quality scores. Br J Nutr 97, 219-231.
16. Fogli-Cawley JJ, Dwyer JT, Saltzman E, et al. (2006) The 2005 Dietary Guidelines for Americans Adherence Index: development and application. J Nutr 136, 2908-2915.

17. Australian Institute of Health and Welfare (2007) Australian Diet Quality Index Project. Canberra: AIHW.

18. Attebo K, Mitchell P \& Smith W (1996) Visual acuity and the causes of visual loss in Australia. The Blue Mountains Eye Study. Ophthalmology 103, 357-364.

19. Willett WC, Sampson L, Browne ML, et al. (1988) The use of a self-administered questionnaire to assess diet four years in the past. Am J Epidemiol 127, 188-199.

20. Barclay AW, Flood VM, Brand-Miller JC, et al. (2008) Validity of carbohydrate, glycaemic index and glycaemic load data obtained using a semi-quantitative food-frequency questionnaire. Public Health Nutr 11, 573-580.

21. Smith W, Mitchell P, Webb K, et al. (1998) Validity and reproducibility of a self-administered food frequency questionnaire in older people. Aust $N Z J$ Public Health 22, 456-463.

22. Foster-Powell K, Holt SH \& Brand-Miller JC (2002) International table of glycemic index and glycemic load values: 2002. Am J Clin Nutr 76, 5-56.

23. National Health and Medical Research Council (2003) Dietary Guidelines for Australian Adults. Canberra: NHMRC.

24. Smith A, Kellet E \& Schmerlaib Y (1998) The Australian Guide to Healthy Eating, pp. 1-40. Canberra: Commonwealth of Australia.

25. Black AE (2000) The sensitivity and specificity of the Goldberg cut-off for EI:BMR for identifying diet reports of poor validity. Eur J Clin Nutr 54, 395-404.

26. Craig CL, Marshall AL, Sjostrom M, et al. (2003) International physical activity questionnaire: 12-country reliability and validity. Med Sci Sports Exerc 35, 1381-1395.

27. Hubbard LD, Brothers RJ, King WN, et al. (1999) Methods for evaluation of retinal microvascular abnormalities associated with hypertension/sclerosis in the Atherosclerosis Risk in Communities Study. Ophthalmology 106, 2269-2280.

28. Sherry LM, Wang JJ, Rochtchina E, et al. (2002) Reliability of computer-assisted retinal vessel measurement in a population. Clin Experiment Ophthalmol 30, 179-182.

29. Wright S (1934) The method of path coefficients. Ann Math Stat 5, 161-215.

30. Willett W (1990) Reproducibility and validity of foodfrequency questionnaires. In Nutritional Epidemiology, pp. 92-126 [W Willett, editor]. Oxford: Oxford University Press.

31. Sun C, Wang JJ, Mackey DA, et al. (2009) Retinal vascular caliber: systemic, environmental, and genetic associations. Surv Ophthalmol 54, 74-95.

32. Liew G \& Wang JJ (2007) Retinal vascular signs in diabetes and hypertension - review. Arq Bras Endocrinol Metabol 51, $352-362$.

33. McGeechan K, Liew G, Macaskill P, et al. (2008) Risk prediction of coronary heart disease based on retinal vascular caliber (from the Atherosclerosis Risk In Communities [ARIC] Study). Am J Cardiol 102, 58-63.

34. Wang JJ, Liew G, Wong TY, et al. (2006) Retinal vascular calibre and the risk of coronary heart disease-related death. Heart 92, 1583-1587.

35. Wang JJ, Liew G, Klein R, et al. (2007) Retinal vessel diameter and cardiovascular mortality: pooled data analysis from two older populations. Eur Heart J 28, 1984-1992.

36. Leung H, Wang JJ, Rochtchina E, et al. (2003) Relationships between age, blood pressure and retinal vessel diameters 
in an older population. Invest Ophthalmol Vis Sci $\mathbf{4 4}$, 2900-2904.

37. Gopinath B, Baur LA, Teber E, et al. (2011) Effect of obesity on retinal vascular structure in pre-adolescent children. Int J Pediatr Obes 6, e353-e359.

38. Kifley A, Liew G, Wang JJ, et al. (2007) Long-term effects of smoking on retinal microvascular caliber. Am J Epidemiol 166, 1288-1297.

39. Wong TY, Islam FM, Klein R, et al. (2006) Retinal vascular caliber, cardiovascular risk factors, and inflammation the multi-ethnic study of atherosclerosis (MESA). Invest Ophthalmol Vis Sci 47, 2341-2350.

40. Fung TT, McCullough ML, Newby PK, et al. (2005) Dietquality scores and plasma concentrations of markers of inflammation and endothelial dysfunction. Am J Clin Nutr 82, 163-173.

41. Nagaoka T, Kuo L, Ren Y, et al. (2008) C-reactive protein inhibits endothelium-dependent nitric oxide-mediated dilation of retinal arterioles via enhanced superoxide production. Invest Ophthalmol Vis Sci 49, 2053-2060.

42. Hoebeeck LI, Rietzschel ER, Langlois M, et al. (2011) The relationship between diet and subclinical atherosclerosis: results from the Asklepios Study. Eur J Clin Nutr 65, 606-613.

43. Klein R, Klein BEK, Knudtson MD, et al. (2006) Are inflammatory factors related to retinal vessel caliber? The Beaver Dam Eye Study. Arch Ophthalmol 124, 87-94.

44. Ikram MK, de Jong FJ, Vingerling JR, et al. (2004) Are retinal arteriolar or venular diameters associated with markers for cardiovascular disorders? The Rotterdam Study. Invest Ophthalmol Vis Sci 45, 2129-2134.

45. Wong TY, Hubbard LD, Klein R, et al. (2002) Retinal microvascular abnormalities and blood pressure in older people: the Cardiovascular Health Study. $\mathrm{Br}$ J Ophthalmol 86 , 1007-1013.

46. Cade JE, Burley VJ, Warm DL, et al. (2004) Food-frequency questionnaires: a review of their design, validation and utilisation. Nutr Res Rev 17, 5-22.

47. Seymour JD, Calle EE, Flagg EW, et al. (2003) Diet Quality Index as a predictor of short-term mortality in the American Cancer Society Cancer Prevention Study II Nutrition Cohort. Am J Epidemiol 157, 980-988.

48. Fung TT, Rexrode KM, Mantzoros CS, et al. (2009) Mediterranean diet and incidence of and mortality from coronary heart disease and stroke in women. Circulation 119, 1093-1100.

49. McNaughton SA, Ball K, Crawford D, et al. (2008) An index of diet and eating patterns is a valid measure of diet quality in an Australian population. J Nutr 138, 86-93.

50. Ibiebele TI, Parekh S, Mallitt KA, et al. (2009) Reproducibility of food and nutrient intake estimates using a semiquantitative FFQ in Australian adults. Public Health Nutr 12, $2359-2365$.

51. McCullough ML, Feskanich D, Stampfer MJ, et al. (2002) Diet quality and major chronic disease risk in men and women: moving toward improved dietary guidance. Am J Clin Nutr 76, 1261-1271

52. Schatzkin A, Kipnis V, Carroll RJ, et al. (2003) A comparison of a food frequency questionnaire with a 24-hour recall for use in an epidemiological cohort study: results from the biomarker-based Observing Protein and Energy Nutrition (OPEN) study. Int J Epidemiol 32, 1054-1062.

53. Michels KB \& Schulze MB (2005) Can dietary patterns help us detect diet-disease associations? Nutr Res Rev 18, 241-248. 